\title{
Correction to: Photoconductivity properties of silver-doped zinc oxide films
}

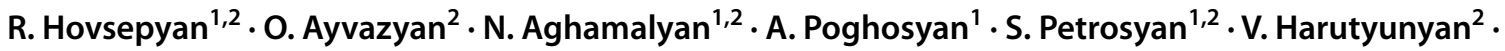 \\ Y. Kafadaryan ${ }^{1,2}$
}

Published online: 9 September 2021

(c) The Author(s), under exclusive licence to Springer-Verlag GmbH, DE part of Springer Nature 2021

\section{Correction to: Applied Physics A (2021) 127:727 https://doi.org/10.1007/s00339-021-04806-0}

In the sentence beginning ' $E a$ is given by...' in Results and discussion section of this article, the text 'the Fermi energy, respectively' should have been added.

To read:

$E a$ is given by either $E_{C}-E_{F}$ or $E_{F}-E_{V}$, depending on whether electrons or holes are the charge carriers of the film. $E_{C}, E_{V}$, and $E_{F}$ are the edges of the conduction band, the valence band and the Fermi energy, respectively.
Publisher's Note Springer Nature remains neutral with regard to jurisdictional claims in published maps and institutional affiliations.

The original article can be found online at https://doi.org/10.1007/ s00339-021-04806-0.

Y. Kafadaryan

ekafadaryan@gmail.com

1 Institute for Physical Research of National Academy of Sciences, 0203 Ashtarak-2, Armenia

2 Russian-Armenian University, Hovsep Emin Street 123, 0051 Yerevan, Armenia 